\title{
Assessment of Learning Outcomes Using Team Based Learning
}

\author{
Abuzer Abdalla ${ }^{1}$, Syed Sadat Ali ${ }^{3}$, Danish Anwer ${ }^{2}$ \\ ${ }^{1}$ Lecturer, ${ }^{2}$ Assisstant Professor, Department of Anatomy, Faculty of Medicine, Jazan University, Jazan, Saudi \\ Arabia, ${ }^{3}$ Associate Professor, Department of Physiology, Gujarat Adani Institute of Medical Sciences, KSKV \\ Kachchh University, Bhuj-01, Gujarat
}

\begin{abstract}
Background and Objectives: Team-based learning (TBL) is composed of pre-class self-study, readiness assessment tests individually (iRAT) followed by readiness assessment tests in the team (tRAT), and peer feed evaluation. TBL was implemented in the course of General Embryology for the 2nd year medical students at the Faculty of Medicine, Jazan University (FMJU), KSA, in the Male and Female Sections through the years 2015-2019. This study aims to analyze this experience in two aspects: whether it was implemented accurately maintain unifromity, and whether it achieved the planned outcomes.

Method: TBL implementation at FMJU was calibrated against a Logic Model for TBL implementation. Data was obtained from records of students including the number of students, attendance, exam marks, and peer feedback. Description of facilities and faculty was also included.

Results: TBL components were applied; multi-disciplinary faculty was involved and an electronic exam replaced paper exam in iRAT, indicating the possibility of improvement. The student shows a high percentage of attendance, high marks in the tRAT compared to tRAT and traditional exams, and high opinion about participation in teamwork.
\end{abstract}

Conclusion: We concluded that TBL implementation was successful in-process and fulfill the intended outcomes.

Keywords: Learning-outcomes, TBL, Logic Model, Assessment, Peer feedback, iRAT, tRAT.

\section{Introduction}

Team-based learning (TBL), was first introduced at Baylor College of Medicine in $2001^{1}$, although the term and concept were first popularized by Larry Michelson, while at the University of Oklahoma in the 1970s. It is a well-defined instructional strategy used in business and science courses. TBL brings together theoreticallybased and empirically-grounded strategies for ensuring the effectiveness of small-groups working independently

\footnotetext{
Corresponding Author:

Dr. Syed Sadat Ali

Associate Professor, Department of Physiology, Gujarat Adani Institute of Medical Sciences, Bhuj-01, Gujarat e-mail: drsadatali@gmail.com

Ph.: +919964318714
}

in classes with high student-faculty ratios (e.g., up to 200:1) without losing the benefits of faculty-led small groups with lower ratios (e.g., 7:1)..$^{2-4}$

Team-based learning consists of modules that can be taught in a three-step cycle: preparation, in-class readiness assurance testing, and application-focused exercise.

The implementation of TBL is based on four underlying principles according to Michaelsen \& Richards, 2005. ${ }^{5}$

1. Groups should be properly formed and groups should have an evenly distributed number of talented people among them. According to Michaelsen, most of the reported "problems" with learning groups (free-riders, member conflict, etc.) are the direct result of inappropriate group assignments". 
2. Students are accountable for their pre-learning and teamwork.

3. Team assignments should promote learning and team development.

4. Students must receive frequent and immediate feedback.

This study aims to evaluate TBL implementation in the course of General Embryology for 2nd class, medical students which took place in the Faculty of Medicine, Jazan University (JUFM); Kingdom of Saudi Arabia (KSA). The implementation started more than 5 years ago and is still going on. In Jazan University, like other Saudi universities, there are separate sections for male and female students, so TBL was conducted in the male and female sections separately but at the same time to ensure the confidentiality of assessment. We conduct this thorough analysis to answer the question of whether TBL at JUFM, KSA, was applied properly and reach the intended learning outcomes. Besides, in this year (20192020) electronic program to answer tests were added, which was different from the previous 4 years. This might indicate the possibility of improvement of TBL at JUFM a year after year.

\section{Materials and Method}

The TBL project at JUFM was evaluated by a mixed-method model with quantity and quality options, using implicit and quasi designs. Targets are the patches of 2nd-year students in JUFM in the male and female sections through the years 2015-2019. The inclusion criterion applies to registered students in the course of General Embryology (total coverage). Exclusion criteria included students who withdrew from the course. Ethical and departmental confidentiality were considered. Ethical clearance was obtained by Institutional Ethical Committee.

We calibrated the TBL at JUFM against the Logic Model ${ }^{6,7}$ for TBL implementation, putting in mind any modification or improvement. The variables were arranged into four categories: inputs, activities/process, output, and outcome. The data was collected using the description of the facility, the human task-force, records of marks, and student peer feedback. Data were analyzed using SPSS for numerical variables. T-test was used for measuring the significant differences. $\mathrm{P}<0.05$ was considered significant.

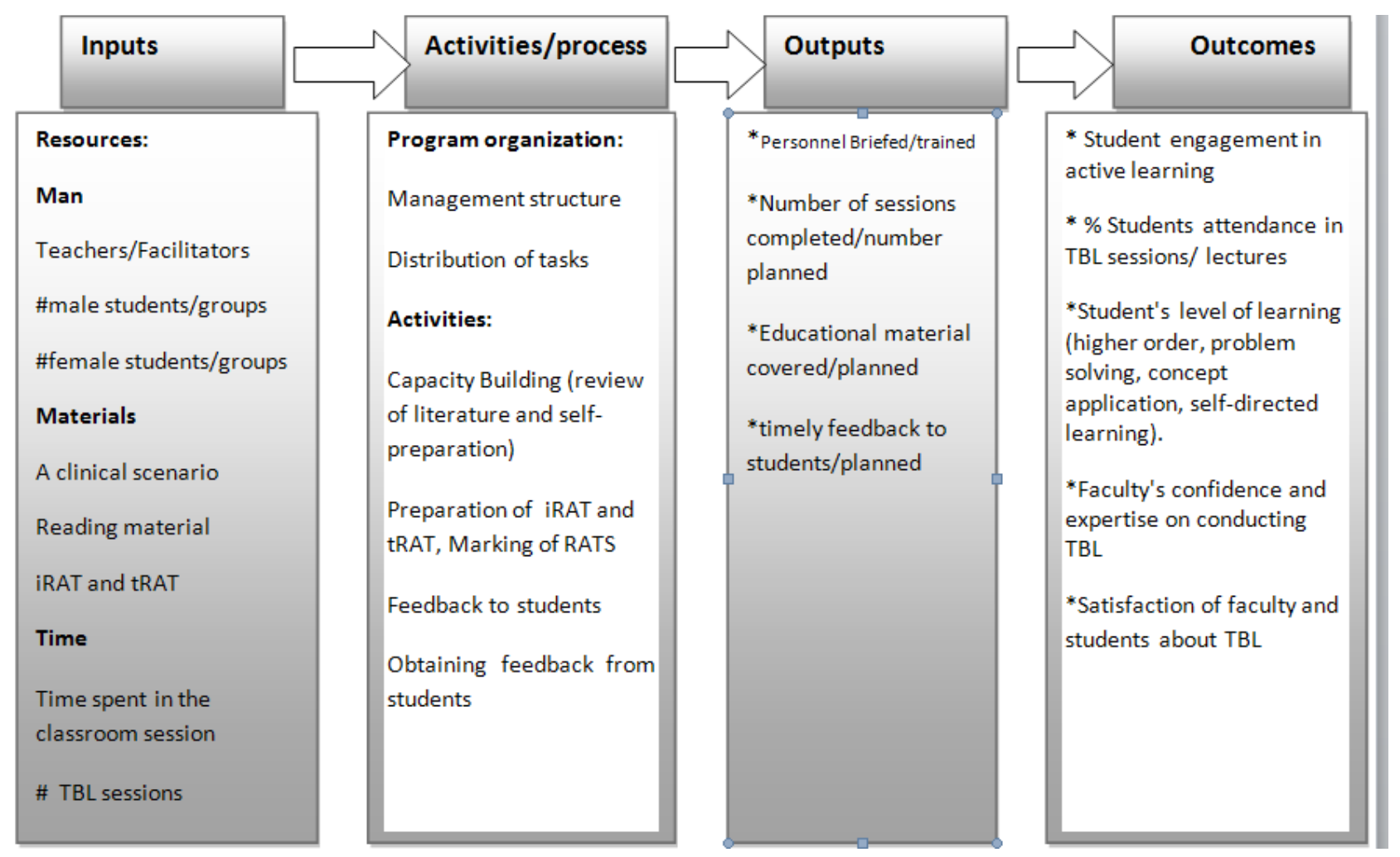

Figure No. 1: Logic model for TBL implementation ${ }^{[7]}$ 


\section{Results}

The analysis of the TBL project in General Embryology at FMJU covered the following: the TBL process as input; the marks and the student perception as an outcome.
Components of the TBL process: These are (1) Description of the Facility, (2) Faculty shared in the preparation and running of TBL (multidisciplinary), (3) students- males and females (4) Study materials (5) the Readiness Assessment Tests (RATs + ) (6) time of a session and the number of sessions/year. They are shown in table 1(a) \& 1 (b).

\section{Students Information:}

Table No. 1 (a): Components of the TBL process through years 2015-19

\begin{tabular}{|c|c|c|c|c|c|}
\hline Component/year & 2015 & 2016 & 2017 & 2018 & 2019 \\
\hline Number of students & $\begin{array}{l}\text { Male: } 105: \\
\text { Female: } 108\end{array}$ & $\begin{array}{l}\text { Male: } 91: \\
\text { Female: } 92\end{array}$ & $\begin{array}{l}\text { Male: } 116: \\
\text { Female: } 111\end{array}$ & $\begin{array}{l}\text { Male: } 115: \\
\text { Female: } 103\end{array}$ & $\begin{array}{l}\text { Male: } 79: \\
\text { Female: } 82\end{array}$ \\
\hline $\begin{array}{l}\% \text { of student attendance in } \\
\text { TBL1 session }\end{array}$ & $\begin{array}{l}\text { Male: } 90.4: \\
\text { Female: } 91.5\end{array}$ & $\begin{array}{l}\text { Male: } 92.3: \\
\text { Female: } 97.5\end{array}$ & $\begin{array}{l}\text { Male: } 96.4: \\
\text { Female: } 97.3\end{array}$ & $\begin{array}{l}\text { Male: } 95.6: \\
\text { Female: } 100\end{array}$ & $\begin{array}{l}\text { Male: } 98.7: \\
\text { Female: } 96.3\end{array}$ \\
\hline $\begin{array}{l}\% \text { of student attendance in } \\
\text { TBL2 session }\end{array}$ & $\begin{array}{l}\text { Male: } 88,5: \\
\text { Female: } 89.5\end{array}$ & $\begin{array}{l}\text { Male: } 94.6: \\
\text { Female: } 95.2\end{array}$ & $\begin{array}{l}\text { Male: } 94.2: \\
\text { Female: } 97.3\end{array}$ & $\begin{array}{l}\text { Male: } 94.8: \\
\text { Female: } 98.0\end{array}$ & $\begin{array}{l}\text { Male: } 96.2: \\
\text { Female: } 92.7:\end{array}$ \\
\hline No of groups of students & $\begin{array}{l}\text { Male: } 10: \\
\text { Female: } 10\end{array}$ & $\begin{array}{l}\text { Male: } 10: \\
\text { Female: } 10\end{array}$ & $\begin{array}{l}\text { Male: } 10: \\
\text { Female: } 10\end{array}$ & $\begin{array}{l}\text { Male: } 10: \\
\text { Female: } 1\end{array}$ & $\begin{array}{l}\text { Male: } 8: \\
\text { Female: } 8\end{array}$ \\
\hline No of classrooms used & $\begin{array}{l}\text { Male: } 2: \\
\text { Female: } 1\end{array}$ & $\begin{array}{l}\text { Male: } 2: \\
\text { Female: } 1\end{array}$ & $\begin{array}{l}\text { Male: } 2: \\
\text { Female: } 1\end{array}$ & $\begin{array}{l}\text { Male: } 1: \\
\text { Female: } 1\end{array}$ & $\begin{array}{l}\text { Male: } 1: \\
\text { Female: } 1\end{array}$ \\
\hline Faculty: & $\begin{array}{l}\text { M-Section: } 4 \\
\text { F-Section 3: }\end{array}$ & $\begin{array}{l}\text { M-Section: } 4 \\
\text { F-Section 3: }\end{array}$ & $\begin{array}{l}\text { M-Section 2: } \\
\text { F-Section 3: }\end{array}$ & $\begin{array}{l}\text { M-Section 1: } \\
\text { F-Section 4: }\end{array}$ & $\begin{array}{l}\text { M-Section 3: } \\
\text { F-Section 4: }\end{array}$ \\
\hline
\end{tabular}

Table 1 (b): Learning Materials, iRAT and tRAT tests

\begin{tabular}{|l|c|c|c|c|c|}
\hline Component/Year & $\mathbf{2 0 1 5}$ & $\mathbf{2 0 1 6}$ & $\mathbf{2 0 1 7}$ & $\mathbf{2 0 1 8}$ & $\mathbf{2 0 1 9}$ \\
\hline $\begin{array}{l}\text { Study Material (Langman's Text book } \\
\text { of Medical Embryology, Sadler, T.W., }\end{array}$ & 9th Edition & 9th Edition & 12th Edition & 12th Edition & 13th Edition \\
\hline No of questions in iRAT/tRAT & 5 & 5 & 5 & 5 & 5 \\
\hline Time to answer iRAT & $5 \mathrm{~min}$ & $5 \mathrm{~min}$ & $5 \mathrm{~min}$ & $5 \mathrm{~min}$ & $5 \mathrm{~min}$ \\
\hline Time to answer tRAT & $\geq 5 \mathrm{~min}$ & $\geq 5 \mathrm{~min}$ & $\geq 5 \mathrm{~min}$ & $\geq 5 \mathrm{~min}$ & $\geq 5 \mathrm{~min}$ \\
\hline Using Paper/E-Moodle test for RATs & Paper & Paper & Paper & Paper & $\begin{array}{c}\text { IRAT: Paper } \\
\text { tRAT: Electronic (Moodle) }\end{array}$ \\
\hline
\end{tabular}

Marks: The marks of tRAT in TBL were high when compared to iRAT and the final exam in General embryology, as shown in the graph (1) below.

Student Feedback Survey: These were analyzed in two parts: (1) Peer feedback of students on each other, which was taken during TBL sessions (graph 2). (2) Student Satisfaction Survey, which was taken later after the issue of the final results and includes points of satisfaction of students about TBL, the staff, and the marks. Both surveys seek the student feedback plotted on the Likert scale from 1-5. (Graph 3). 

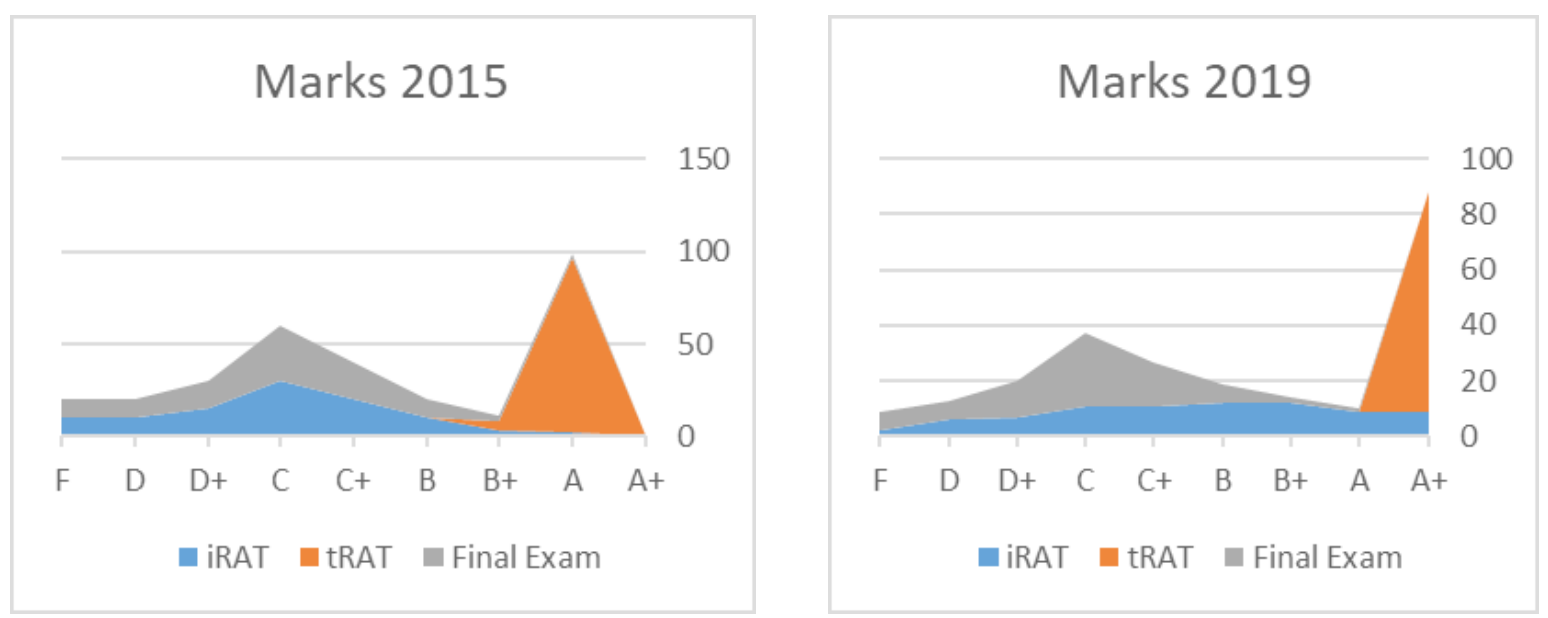

Graph No. (1): Comparison between marks in the two extreme years of this study (2015-2019)
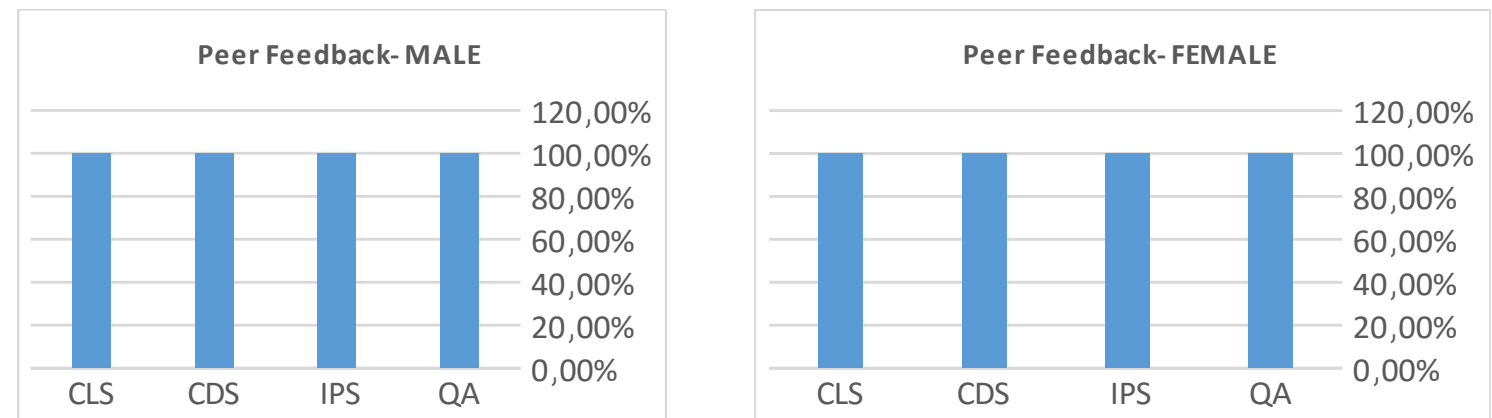

CLS: Cooperative Learning Skills, CDS: Self-Directed Learning, IPS: Interpersonal Skills, QA: Qualitative Assessment.

Graphs No. (2): TBL Peer Feedback, male and female students.

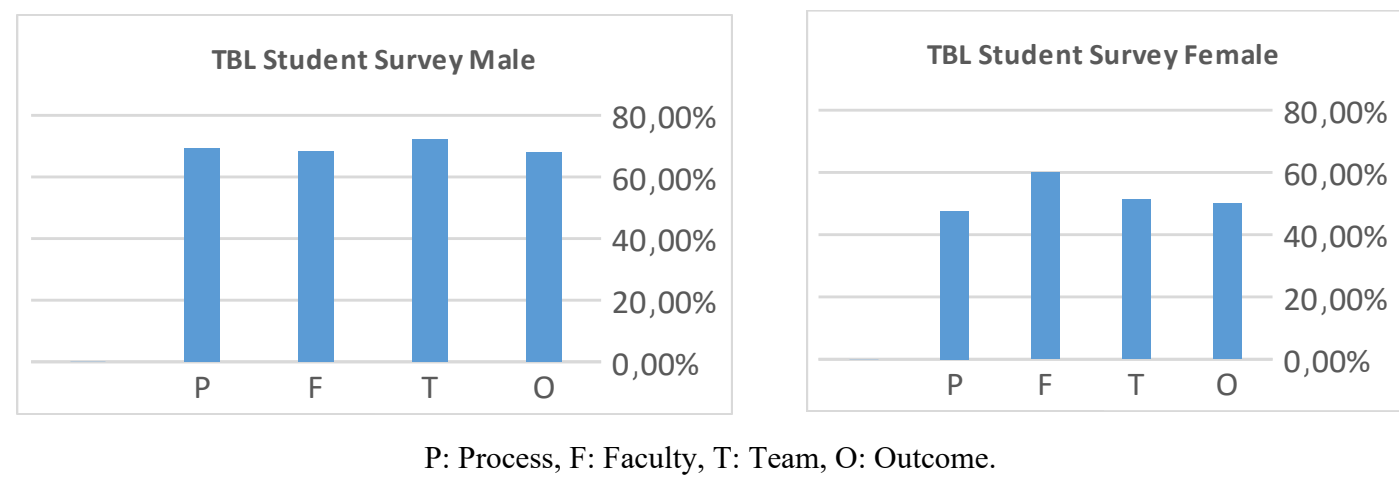

Graph No. (3): TBL Student Survey, male and female students.

\section{Discussion}

Team-Based Learning has been gaining traction in academic institutions, especially in the field of medicine. Out of all 144 medical schools in the US, at least $83 \%$ use TBL pedagogy. 44 of those institutions also have faculty or staff who are part of the Team-Based Learning Collaborative (TBLC), an international collaborative that focuses on connecting TBL practitioners, sharing
TBL resources, and promoting best practices. Within the top 50 medical schools in the US, $92 \%$ use TBL pedagogy. Team-based learning (TBL), when properly implemented, includes many, if not all, of the common elements of evidence-based best practices. ${ }^{8}$

The implementation of TBL in the Embryology module at the Faculty of Medicine, Jazan University, KSA was mentioned before in two posters, but none of 
them conduct a thorough analysis and they didn't answer the question whether TBL was applied properly or reach the intended learning outcomes. Besides, the previous two posters were written by an internal reviewer from the Department of Anatomy, and this study was written in collaboration with an external reviewer from the Department of Physiology.

The Implementation Process of TBL: TBL in FMJU consists of five essential steps: (1) Individual pre-class learning of a defined topic, triggered by a scenario of a problem, and guided study material was specified from a textbook of GE (2)Individual Readiness Assurance Test (IRAT) in which a student answers a set of MCQ questions individually (3)Team Readiness Assurance Test (TRAT), in which, after answering the IRAT, the students form teams and answer the same test within the team (4) Clarification session, in which instructors facilitate a discussion or debate among teams to consider the possible solutions to the application problem and reach final correct answers to the MCQ of IRAT- TRAT2 and (5) Peer feedback, in which students give feedback to which degree a member of their group is collaborative. These steps were the model of TBL adopted in other universities3, only some universities use scratch cards for tRATS. Two sessions were conducted each year, one hour for each session. The time of a session may extend for more than two hours, spent partly in the redistribution of the groups of students, but most often because the students enjoyed the debates on explanation when they select more than one answer to a question. This brainstorming is a high positive outcome of TBL.

The Facility \& the Faculty: The Male and Female Sections in the FMJU in the first 3 years of the study (2015-17) were placed side by side in one large campus, separated only by prohibited-to mix walls. In the last 2 years (20018-19) the Male Section was relocated to a new campus at the other end of the City of Jazan. This arranged at the beginning-end time of the sessions only through telephones. The faculty shared in the preparation and running of TBL were multidisciplinary from Departments of Anatomy, Physiology, Pathology, Obstetrics, and Gynecology. This gave a sense of integration with other disciplines, especially the Gynecology1 staff, who provided the students with a valuable clinical application on the cases. In the last year in TBL, a single professor was able to direct the male class all alone, without losing "the effectiveness of small-groups working independently in classes with high student-faculty ratio4 - (115:1)".

The Students: The number of students shows variation from year to year, but in all years the attendance to TBL sessions was high compared to lectures. The male and female students were planned to start the sessions at the same time normally at $1 \mathrm{pm}$ to avoid the transfer of the iRAT questions. Although they are far apart and not allowed to mix, male and female students have continuous secret phone-connections.

Study materials and the Readiness tests: The chapters of General Embryology included in the TBL were not taught in lectures and were completely selflearning. The Readiness Assessment Tests RATs were the 5 best answer questions of higher-order classification. The textbook used for study material was Langman's Medical Embryology, Sadler, T.W, and 9th Edition. Williams and Wilkins Co., Baltimore. The editions were updated up to the 13th edition. Each session was formed of a set of 5 MCQs which students first had to answer individually (iRAT), then in groups (tRAT). Modification of using papers to print the tests took place from year to year. At first expensive colored answer sheets marked by the machine were used. Then on the demand of the administration, a table was plotted in the question papers for the answers. This year E-learning Moodle Program was used for tRAT which enabled students to use tabs and mobile devices to answer. These were improvements in the cost-effectiveness with harm to the core process of TBL.

Students achievement of learning outcomes: The marks of TBL were added to the final marks of General Embryology, and this motivated the students and made them take TBL seriously. Marks of the iRAT were like the marks of a student in other section of the final exam, some students were very high and some students low. Marks of tRAT were the high, most often full mark, as they were the result of the work of many brains together, and this is a great positive outcome which proves that TBL is a "powerful and versatile teaching strategy that enables teachers to take small group learning to a whole new level of effectiveness". ${ }^{1}$ When marks of TBL were added to the other marks, they enhance the final grade. In General Embryology, which was a great pleasure to the students.

Student satisfaction: In the Peer Feedback, the students seemed to have a high opinion on each other, or they might benefit from this high opinion as Peer 
Feedback has a mark in the final grade. The student satisfaction about the TBL as a whole is important in the maintenance of TBL and for putting action plans for improvement, and of course research studies about TBL in FMJU.

\section{Conclusion}

Implementation of TBL in the course of General Embryology was analyzed in two points: the process of implementation and the outcome. We concluded that the TBL implementation in FMJU was successful. This was indicated by many points: it was applied continuously for 5 years and gained acceptance from the students and faculty. Multi-disciplinary teachers were involved. Components of TBL process were almost highly fulfilled including iRAT, tRAT and peer feedback. It was even more improved by electronic tRAT. Students show a high percentage of attendance, were self-dependent in reading the study materials, were cooperative in team learning $\&$ assessment, and scored high marks, that is, they were interested and gained valuable experience from TBL, thereby, achieving the assigned learning outcomes of the module. The drawbacks were the class rooms in male section, and the female to male discrepancy in the number and specialty of teachers.

\section{Conflict of Interest: Nil}

\section{Source of Funding: Self}

\section{References}

1. Michaelsen, LK, Watson WE., Cragin, JP, and Fink LD. Team-based learning: A potential solution to the problems of large classes. Exchange: The
Organizational Behavior Teaching Journal 1982; 7(4):18-33.

2. Michaelsen, LK. Knight, AB, \& Fink LD. Teambased learning: A transformative use of small groups in college teaching.| 2004

3. Koles PG, Stolfi, A, Borges NJ, Nelson S and Parmelee DX. (2010). The impact of teambased learning on medical students' academic performance. Academic Medicine, 2010; 85(11):1739-45.

4. Haidet P, Levine RE, Parmelee DX, Crow S, Kennedy F, Kelly PA et al. Perspective: Guidelines for reporting team-based learning activities in the medical and health sciences education literature. Academic Medicine, 2012; 87(3):292-99.

5. Michaelsen L and Richards B. "Concluding the team-learning literature in health sciences education: a commentary". Teaching and Learning in Medicine. 2005; 17 (1): 85-88. DOI: 10.1207/ s15328015tlm1701_15. PMID 15691820.

6. Newcomer K., Hatry H. and Wholey J. Planning and designing useful evaluations. 3rd edition. Handbook of practical program evaluation. San Fransisco: John Wiley \& Sons, Inc, 2010(19).

7. Vasan, $\mathrm{N}$ and DeFouw D. The outcomes logic model: An approach for program planning and evaluation: Taking successful pilot programs to scale: Evolution of TBL anatomy program, 2010.

8. Michaelsen, L. K, and Sweet, M. Team-based learning. New directions for teaching and learning, 2011;(128):41-51. 